\title{
Occurrence of odour-causing compounds in different source waters of China
}

\author{
J. W. Yu, Y. M. Zhao, M. Yang, Tsair-Fuh Lin, Z. H. Guo, \\ J. N. Gu, S. Li and W. Han
}

\begin{abstract}
In this study, occurrence of the main odorous compounds in different types of source water in China, including rivers, lakes and reservoirs, were investigated by integrating the methods of flavour profile analysis (FPA) and sensory-GC/MS analysis. Simultaneous distillation extraction (SDE) was chosen as the preconcentration technique while the odour-causing compounds were identified with sensory-GC/MS. It was found that MIB, which is mainly produced by some cyanobacteria and actinomycetes, was one of the most widely distributed odour-causing compounds, regardless of source type. A peak MIB concentration of approximately $170 \mathrm{ng} \mathrm{I}^{-1}$ was recorded in MY Reservoir in October 2005. Among the nine investigated sites, YH Reservoir in Hebei Province was the only site showing geosmin production. A peak geosmin concentration exceeding $7,000 \mathrm{ng}^{-1}$ was detected in July 2007. In June 2007, a serious taste/odour (T/O) event occurred in Wuxi City, and the offensive flavour was a strong septic or marshy odour caused by dimethyl trisulfide (431 $\mathrm{ngl}^{-1}$ in finished water). Septic/swampy and earthy/musty odours occurred in source waters of Shanghai and Guangzhou. It was found that dimethyl trisulfide was mainly responsible for the septic/swampy odour and MIB for the earthy/musty one. Dimethyl trisulfide might be an important T/O-causing compound in China.

Key words | bis(2-chloroisopropyl) ether, dimethyl trisulfide, geosmin, MIB, sensory-GC/MS

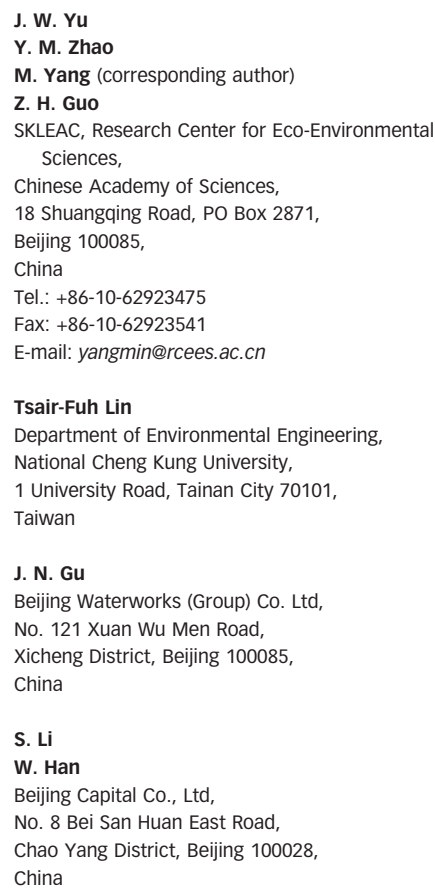

\section{INTRODUCTION}

Taste/odour (T/O) problems are important for the drinking water industry, because consumers usually judge water quality by what they first perceive (Bowmer et al. 1992; Ishida \& Miyaji 1992). The origins of $\mathrm{T} / \mathrm{O}$ problems in drinking water are often found in source water (Izaguirre et al. 1999; Lin et al. 2002). Taste/odour problems commonly have microbial (e.g. cyanobacteria, actinomycetes) and chemical (e.g. source water pollution from industrial discharge, surface runoff) sources. In addition to some well-known biogenic metabolites such as MIB and geosmin which cause earthy-musty odours (Yagi et al. 1985;
Jensen et al. 1994; Izaguirre et al. 1999), attention should be paid to other odorous compounds.

Identification of the odour-causing compounds is vital for the control of $\mathrm{T} / \mathrm{O}$ problems and the improvement of the organoleptic quality of potable water. Flavour profile analysis (FPA) is one of the most popular methods to assess the sensory properties of drinking and related waters, and can be used to quantify the T/O intensity of water samples (Mallevialle \& Suffet 1987; Rashash et al. 1997). To analyse the $\mathrm{T} / \mathrm{O}$ compounds at the $\mathrm{ngl}^{-1}$ level or less, gas chromatography/mass spectrometry (GC/MS) has often 
been applied by coupling with some concentration techniques such as liquid-liquid extraction (LLE), closed-loop stripping analysis (CLSA), simultaneous distillation extraction (SDE), or purge and trap equipment (Mallevialle \& Suffet 1987; Khiari et al. 1995; Lloyd et al. 1998; Hassett \& Rohwer 1999). Because of its rapidity, simplicity and ease of automation, solid-phase microextraction (SPME) has become very popular for environmental analysis, and has been successfully applied to the quantification of some odorous compounds such as MIB and geosmin (Lloyd et al. 1998; Watson et al. 2000). To attribute the overall odour of the water sample to specific chemicals, the sensory-GC technique, which allows for the simultaneous identification of trace organics and description of their odours, is a useful technique (Khiari et al. 1992; Young et al. 1999).

In China, with the deterioration of source water quality, more and more drinking water T/O events have occurred, attracting a lot of public attention (Guo 2008; Yang et al. 2008). In this study, occurrence of the main odorous compounds in different types of source water in China, including rivers, lakes and reservoirs, were investigated by integrating the methods of flavour profile analysis (FPA) and sensory-GC/MS analysis. Such general investigations can provide basic data on the main odour profiles in source waters, which is helpful for the improvement of drinking water quality. In addition, the typical odour compounds responsible for several recent $\mathrm{T} / \mathrm{O}$ events in China were also evaluated.

\section{METHODS}

\section{Sampling points}

From 2005 to 2007, source water from eight cities in China (illustrated in Figure 1), including Beijing, Tianjin, Chongqing, Shanghai, Shenzhen, Zhengzhou (Henan Province), Guangzhou (Guangdong Province) and Qinhuangdao (Hebei Province), was sampled periodically in different seasons. Cities using a river type water source include Tianjin, Zhengzhou, Chongqing, Guangzhou and Shanghai, and those using a reservoir type include Beijing (MY Reservoir), Shenzhen (DH Reservoir) and Qinhuangdao (YH Reservoir). All water samples were collected at the intake of the water treatment plant, and $0.1 \mathrm{gl}^{-1} \mathrm{HgCl}_{2}$ was

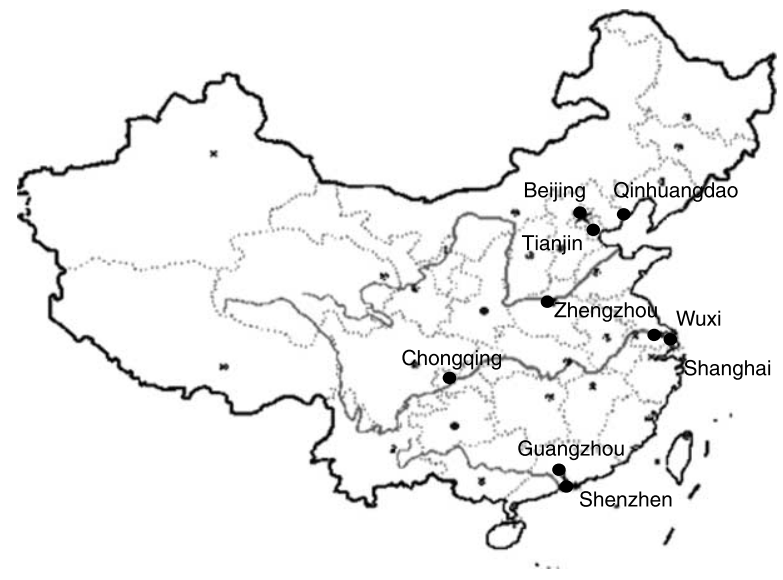

Figure 1 | Distribution of sampling sites.

added to prevent bacteria activity. In addition, source water samples were collected during one typical odour event occurring in 2007 in Wuxi City, Jiangsu Province. All samples were stored in a refrigerator and analysed within 4 days.

\section{Chemicals and materials}

The organic solvents methanol and methylene chloride were products of Fisher (pesticide grade, USA). Odorous compound standards of MIB, geosmin, heptanal, benzaldehyde, dimethyl trisulfide, benzeneacetaldehyde, 1-octen3-ol, bis(2-chloroisopropyl) ether, menthol, and ß-Ionone were purchased from Sigma-Aldrich Co., USA. Stock solution of $1 \mathrm{mgl}^{-1}$ was prepared by diluting different standard solutions with ultra-pure water (resistivity $\geq 18$ $\mathrm{m} \Omega \mathrm{cm}$ ). $\mathrm{NaCl}, \mathrm{Na}_{2} \mathrm{SO}_{4}$ and $\mathrm{HgCl}_{2}$ were obtained from Beijing Chemicals Ltd (analytical grade). $\mathrm{NaCl}$ and $\mathrm{Na}_{2} \mathrm{SO}_{4}$ were purified with respect to organic impurities by heating to $450^{\circ} \mathrm{C}$ for two hours prior to use.

\section{Extraction of odour-causing compounds}

Three extraction and concentration methods, closed-loop striping analysis (CLSA) (Brechbüler, Switzerland), simultaneous distillation extraction (SDE) and solid phase microextraction (SPME), were compared for their extraction efficiency. CLSA was performed according to a previous study (Young \& Suffet 1999), except that the extraction solvent was methylene chloride instead of carbon 
disulfide. For the SDE method (Young \& Suffet 1999), 3 litres of water sample was concentrated to $0.1 \mathrm{ml}$ of methylene chloride. PDMS/DVB fibre (57310-U, Supelco, America) was chosen for SPME extraction (Watson et al. 2000; Lin et al. 2002). Briefly, the fibre was injected through a silicon-Teflon coated septum and placed into the headspace of a $75 \mathrm{ml}$ extraction vial with $50 \mathrm{ml}$ of water sample; $12.5 \mathrm{~g}$ of $\mathrm{NaCl}$ was added to the sample, and the vial was controlled at a temperature of $65^{\circ} \mathrm{C}$ using a waterjacketed system. Extraction time was controlled at $30 \mathrm{~min}$ under mixing.

\section{FPA and sensory-GC/MS analysis}

Two sensory schemes, including FPA and sensory-GC/MS methods were employed in this study. FPA was used to identify the odour group and intensity of the water samples, while sensory-GC/MS combined with three preconcentration techniques was used for the identification of specific odour-causing compounds. A detailed description of training and applications for the FPA method can be found in Standard Methods (1995). In this study, five non-smokers were trained for the panel, and at least four panellists participated in the test. Based on the consensus of the panel, seven-point scales of 1-12 were used to describe the intensity of samples. Some typical odour-causing compounds, such as dimethyl trisulfide with septic odour, MIB and geosmin with earthy/musty odour and heptanal with grassy odour, were selected as odour references based on the sensory-GC/MS results of our previous studies for the training of FPA panellists to enhance the sensitivity and reproducibility of FPA evaluation. The sensory-GC/MS device consists of an olfactory detection port (Gerstel ODP2, Germany) connected to the GC-MS system, where the effluent from the gas chromatography column is divided into two parts: the first portion is sent to the MS detector while the second goes to the olfactory port and is smelled by the operator. Detailed information can be found in earlier studies (Young \& Suffet 1999; Hochereau \& Bruchet 2004).

\section{GC/MS analysis}

The GC/MS analysis was performed to qualify and quantify the odorous chemicals. A $30 \mathrm{~m} \mathrm{HP}-5 \mathrm{~ms}$ (i.d. $0.25 \mathrm{~mm}$, coating film thickness $0.25 \mu \mathrm{m}$ ) capillary column was used. For the CLSA and SDE extraction method, a $1 \mu \mathrm{l}$ sample was injected in the on-column mode, while for the SPME method, the fibre was introduced directly into the injector after $30 \mathrm{~min}$ exposure time. The GC temperature program was set at $40^{\circ} \mathrm{C}$ for $3 \mathrm{~min}$, raised to $240^{\circ} \mathrm{C}$ at $4^{\circ} \mathrm{C} \mathrm{min}^{-1}$ and kept $5 \mathrm{~min}$. The transfer-line temperature was $280^{\circ} \mathrm{C}$ and ion-trap temperature was $230^{\circ} \mathrm{C}$. The ion-trap mass spectrometer was operated in the EI positive mode $(70 \mathrm{eV})$. For qualitative analysis, the full scan mode from 50 to $400 \mathrm{~m} / \mathrm{z}$ was used for the primary identification of odorous compounds according to the NIST database, then further confirmed using odorous compound standards. Odorous compounds of MIB and geosmin were directly analysed by SPME-GC/MS. The quantitative ion selected for MIB and geosmin were 95 and $112 \mathrm{~m} / \mathrm{z}$, respectively.

\section{RESULTS AND DISCUSSION}

\section{Comparison of extraction methods for sensory-GC/MS analysis}

Water samples were collected from the source water of Shanghai on 25 July 2006, then analysed using sensoryGC/MS after extracting with CLSA, SDE and SPME, respectively. Figure 2 shows the sensory-GC/MS chromatograms of the three extraction techniques. It is clear that, among the three techniques, more odours could be

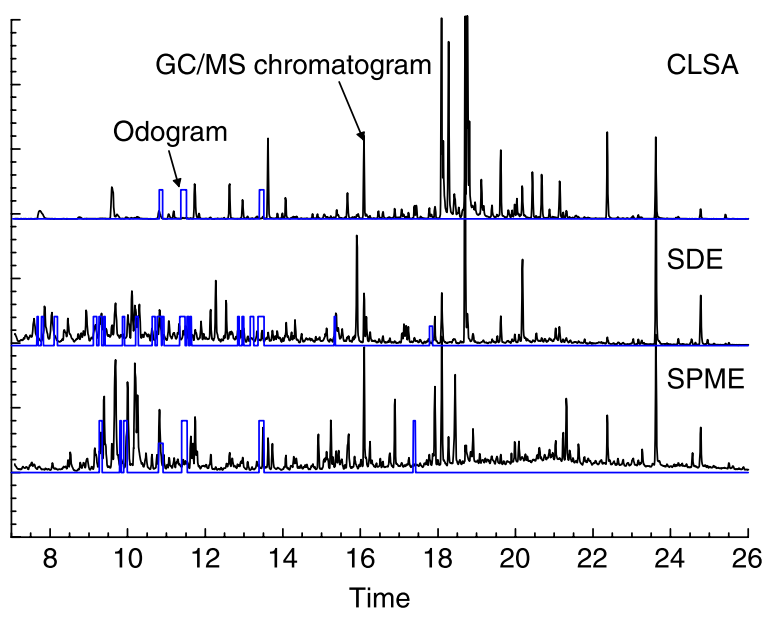

Figure 2 | Sensory-GC/MS chromatogram of Shanghai source water with different extraction methods 
perceived in the SDE sample, while CLSA yielded the lowest number of odours. Most odours perceived in the CLSA and SPME sample could also be found in the SDE sample.

CLSA is usually used for the analysis of nonpolar, volatile organic compounds of intermediate molecular weight (Khiari et al. 1992; Hassett \& Rohwer 1999), and SPME is known for its high selectivity for the extraction of target analytes. The SDE method, on the other hand, could extract a wide range of organic pollutants, such as ketones, aldehydes, alcohols, ethers, esters, fatty acids, and phenols, because of the combination of distillation and solvent extraction (Young \& Suffet 1999; Young et al. 1999). Therefore, the SDE method is suitable for the extraction of samples for the analysis of odour-causing compounds.

The odour of this sample was also assessed using FPA by five trained panellists, and it was described as 'earthy/ musty' and 'septic/swampy' and the intensity was rated at 4 and 6 , respectively. The most intense odour compounds, such as dimethyl trisulfide, bis (2-chloroisopropyl) ether and MIB, were detected by the SDE-sensory-GC/MS analysis. By integrating this result with that of FPA, an earthy/musty odour was assigned to MIB, and a septic and medicinal odour to dimethyl trisulfide and bis (2-chloroisopropyl) ether.

\section{Occurrence of MIB and geosmin in different source waters}

MIB and geosmin are the two most common musty/earthy compounds present in natural water systems (Suffet $e$ t al. 1999). Table 1 displays the concentration ranges of MIB and geosmin. As indicated, MIB was widely distributed in different types of source water in China, while geosmin only occurred in YH Reservoir in Qinhuangdao City.
A MIB odour event occurred in MY Reservoir in Beijing in 2005, and the variations of the MIB concentration were monitored during this period (Figure 3). The event began in August and ended in early November with the peak MIB concentration (162 $\mathrm{ngl}^{-1}$ ) occurring in late September. In the summer of 2007, a geosmin odour event occurred in YH Reservoir in Qinhuangdao, which recorded a peak geosmin concentration of $7,100 \mathrm{ng}^{-1}$. A survey on geosmin variations and algal population dynamics indicated that Anabaena spiroides was mainly responsible for the extremely high geosmin concentration. However, over $85 \%$ of the geosmin remained in the algal cells, which was in accordance with other studies (Rosen et al. 1992; Rashash et al. 1995). It is important to maintain the integrity of algal cells during water treatment to prevent the release of geosmin.

\section{Odour causing compounds in Shanghai and Guangzhou}

Shanghai and Guangzhou have long been known for their T/O problems in drinking water. From 2006 to 2007, the source waters of Guangzhou and Shanghai were evaluated by combining FPA and SDE-sensory-GC/MS analysis, and the results are illustrated in Tables 2 and 3, respectively.

From the FPA results, 'septic/swampy' was the primary odour for the two source waters all year around, and 'earthy/musty' existed with a relatively low FPA intensity. From the sensory-GC/MS analysis, ten different odours were perceived in the two source waters, among which septic/swampy and earthy/musty odours were the two most intense. All corresponding compounds were also identified with the GC/MS NIST library and confirmed with pure standards (Table 3). By integrating the two results, dimethyl trisulfide was assigned to the septic/swampy odour and MIB to the earthy/musty odour. It is interesting that MIB

Table 1 Concentrations of MIB and geosmin in the source water of eight cities

\begin{tabular}{|c|c|c|c|c|c|c|c|c|}
\hline Sampling site & Shanghai & Guangzhou & Chongqing & Tianjin & Zhengzhou & Shenzhen & Beijing & Qinhuangdao \\
\hline Water source type & River & River & River & River & River & Reservoir & Reservoir & Reservoir \\
\hline MIB (ng l-1) & $0-20$ & $0-185$ & $0-15$ & $0-135$ & $0-255$ & $0-15$ & $0-175$ & $0-15$ \\
\hline Geosmin $\left(\mathrm{ng} \mathrm{l}^{-1}\right)$ & $0-15$ & $<10$ & $<10$ & $<10$ & $<10$ & $<10$ & $<10$ & $0-7,200$ \\
\hline
\end{tabular}




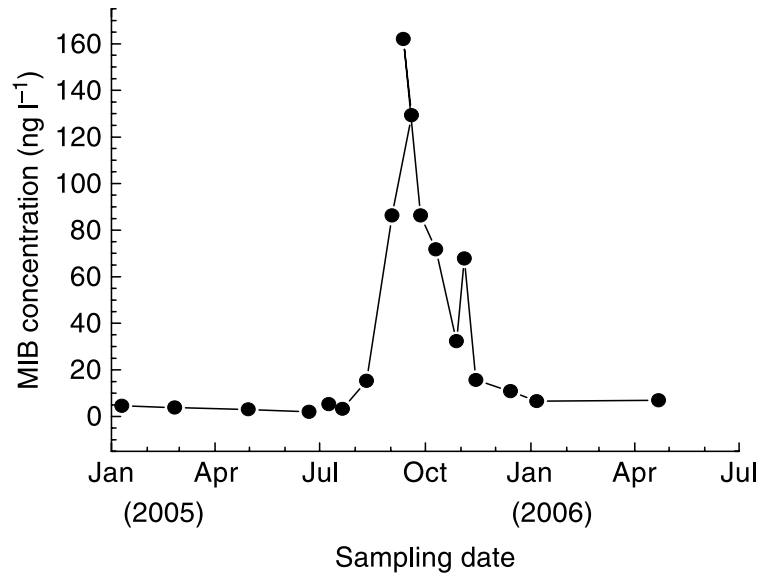

Figure 3 Concentration change of MIB in the source water of Beijing.

existed in river type source waters at a relatively high level. It might be produced by some actinomycetes or benthic cyanobacteria.

On the other hand, dimethyl trisulfide, which has been listed on the 'Taste and Odour Wheel', is one typical compound causing swampy or septic odour, with an odour threshold concentration of $10 \mathrm{ngl}^{-1}$ (Mallevialle \& Suffet I987; Wajon 1988). Several research groups have reported the occurrence of such compounds in drinking water, and concentrations between 5 and $500 \mathrm{ngl}^{-1}$ were reported previously in source waters (Wajon I988; Khiari et al. 1997). In this study, much higher dimethyl trisulfide levels were found in Guangzhou (285-3,963 $\mathrm{ng}^{-1}$ ) and Shanghai source water $\left(1,590-3,665 \mathrm{ng}^{-1}\right)$. It is hypothesized that the notorious odour problems in the two cities were possibly caused by the high concentration of dimethyl

Table 2 | Flavour profile analysis (FPA) of water samples

\begin{tabular}{lll}
\multirow{2}{*}{ Sampling date } & \multicolumn{2}{l}{ Odour description and intensity } \\
Guangzhou source water & Shanghai source water \\
\hline July 2006 & Earthy/musty (5) & Earthy/musty (4) \\
& Septic/swampy (6) & Septic/swampy (6) \\
October 2006 & Earthy/musty (4) & Earthy/musty (4) \\
& Septic/swampy (6) & Septic/swampy (8) \\
January 2007 & Earthy/musty (3) & Earthy/musty (5) \\
& Septic/swampy (8) & Septic/swampy (8) \\
& & medicinal (5) \\
\hline
\end{tabular}

Note: FPA panel includes five trained panellists.

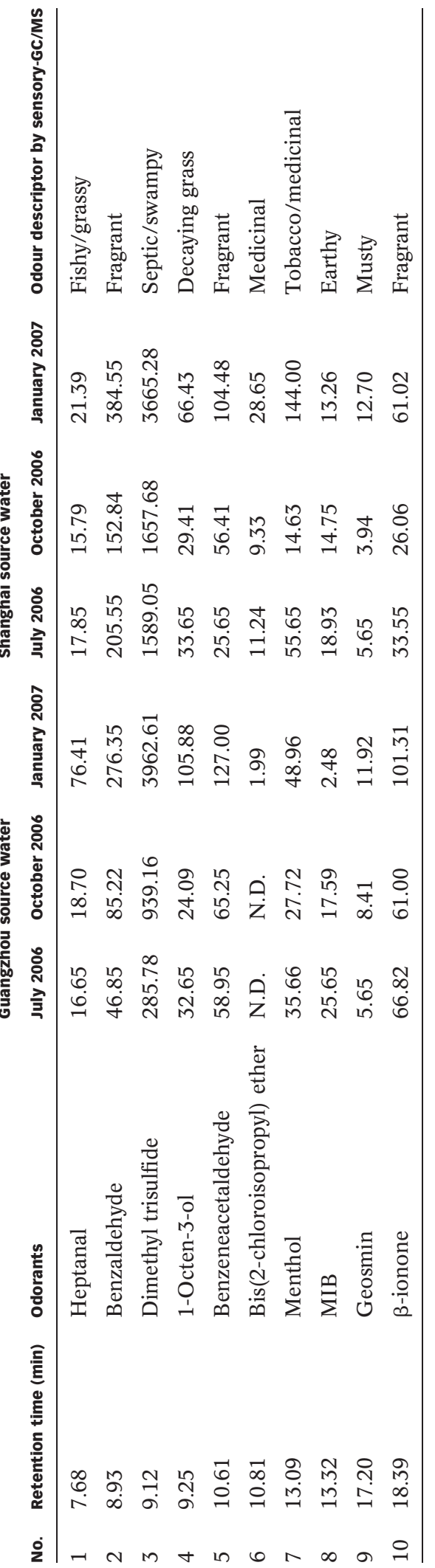


trisulfide. Previous studies have shown that methylated sulfur compounds, including dimethyl trisulfide, can be formed through a number of biological processes in the environment, which include: the degradation of dimethylsulfonium propionate (algal osmoprotectant), bacterial catabolism of sulfur-containing amino acids such as methionine and cysteine, biochemical oxidation of methanethiol, possible methiolation of 2-keto-4-methiobutyrate, and the transfer of methyl groups from methylated aromatics to sulfide by anaerobic bacteria (McCarty et al. I993). These processes can occur under both aerobic and anaerobic conditions, the latter with much faster rates (Fatoki i997).

Besides the above two intense odours, another strong medicinal odour was also perceived at a retention time of $10.81 \mathrm{~min}$ in the SDE-sensory-GC/MS analysis of Shanghai source water. The odour-causing compound was identified as bis(2-chloroisopropyl) ether, the concentrations of which were between 9 and $29 \mathrm{ngl}^{-1}$. The FPA panel gave a medicinal intensity of five for one water sample (Table 3), and the level was quantified as $28.65 \mathrm{ngl}^{-1}$. It should be noted that this compound is listed as a priority pollutant by USEPA.

As discussed above, dimethyl trisulfide and MIB were the two main odour compounds in the source waters of the two cities, and bis(2-chloroisopropyl) ether was another important odour compound in Shanghai. However, the origins of these compounds are not clear, and further studies are needed.

Table 4 | Main odorous compounds detected in the water samples by SDE-sensory-GC/MS

\begin{tabular}{llll} 
odorants & $\begin{array}{l}\text { Concentration }\left(\mathbf{n g} \mathbf{I}^{-\mathbf{1}}\right) \\
\text { Black water }\end{array}$ & Source water of the intake & Finished water \\
\hline Benzaldehyde & 172 & 196 & 1,438 \\
Dimethyl trisulfide & 11,399 & 1,768 & 431 \\
1-Octen-3-ol & 40.3 & 60.1 & 53.0 \\
Benzeneacetaldehyde & 238 & 110 & 58.3 \\
Bis(2-chloroisopropyl) ether & 2.4 & 3.2 & 2.6 \\
Menthol & 69.4 & 68.1 & 13.6 \\
MIB & 112 & 57.1 & 17.6 \\
Decanal & 579 & 228 & 261 \\
Geosmin & 6.6 & 3.4 & 4.8 \\
$\beta$-Ionone & 4,054 & 358 & N.A. \\
\hline
\end{tabular}

\section{Odour causing compounds in Wuxi odour event}

At the end of May 2007, a serious drinking water T/O event occurring in Wuxi City drew the public's attention. A heavy cyanobacterial bloom occurred one month earlier, so the event was originally thought to be caused by the cyanobacterial bloom (Guo 2008). However, an extremely strong septic and marshy odour, not the earthy/musty odour generally occurring during a cyanobacterial bloom, was perceived. Further, the offensive odour only occurred when a huge black water 'agglomerate' entered the water intake (Yang et al. 2008). Samples were collected on 4 June 2007 from the black water agglomerate, source water at the water intake, and the finished water, and dimethyl trisulfide with a concentration of $11,399,1,768$ and $431 \mathrm{ngl}^{-1}$ was detected in the three samples, respectively, according to the SDEsensory-GC/MS analysis (Table 4). Other odour-causing compounds, such as MIB and geosmin, were also detected at a much lower level. According to the FPA results, the septic and marshy odour intensities for the black agglomerate, source water and finished water were 10, 10 and 9, respectively. So, dimethyl trisulfide was considered as one of the main odour compounds responsible for the offensive odour in Wuxi drinking water by integrating the results of FPA and sensory-GC/MS. Anaerobic biodegradation of some biomass containing dead algal cells might have produced such a high concentration of dimethyl trisulfide in the black water agglomerate (McCarty et al. I993; Franzmann et al. 200I). 


\section{CONCLUSIONS}

In this study, occurrence of the main odorous compounds in different types of source water in China was investigated by combining sensory-GC/MS analysis with FPA. Among the three preconcentration techniques, SDE could extract a much wider range of odorous pollutants and was used for the investigation. MIB was found to be widely distributed in both the river and reservoir types of source water, and Yanghe Reservoir in Qinhuangdao was the only one of the nine sites investigated showing a serious geosmin problem. The highest geosmin concentration, exceeding $7,000 \mathrm{ngl}^{-1}$, was detected in July 2007, which was a result of the high density of Anabaena. Septic/swampy and earthy/musty were found to be the main odours in the source waters of Shanghai and Guangzhou. Dimethyl trisulfide was the main compound responsible for the septic/swampy odour in their drinking water, and the serious drinking water odour event in Wuxi City. Bis(2-chloroisopropyl) ether has also been identified as a medicinal odorant in the Shanghai source water.

\section{ACKNOWLEDGEMENTS}

We acknowledge the support provided by National Natural Science Foundation of China (50808171, 50678166 and 50525824) and CAS Major Projects of Knowledge Innovation Program (kzcx1-yw-06-02).

\section{REFERENCES}

Bowmer, K. H., Padovan, A., Oliver, R. L., Korth, W. \& Ganf, G. G. 1992 Physiology of geosmin production by Anabaena circinalis isolated from the Murrumbidgee River, Australia. Water Sci. Technol. 25(2), 259-267.

Fatoki, O. S. 1997 Biomethylation in the natural environment: a review. S. Afr. J. Sci. 93, 366-370.

Franzmann, P. D., Heitz, A., Zappia, L. R., Wajon, J. E. \& Xanthis, K. 200I The formation of malodorous dimethyl oligosulphides in treated groundwater: the role of biofilms and potential precursors. Water Res. 35(7), 1730-1738.

Guo, L. 2008 Doing battle with the green monster of Taihu Lake. Science 317, 1166.

Hassett, A. J. \& Rohwer, E. R. 1999 Analysis of odorous compounds in water by closed-loop stripping with a multichannel silicone rubber trap followed by gas chromatography-mass spectrometry. J. Chromatogr. A 849(2), 521-528.
Hochereau, C. \& Bruchet, A. 2004 Design and application of a GC-Sniff-F/MS system for solving taste and odour episodes in drinking water. Water Sci. Technol. 49(9), 81-87.

Ishida, H. \& Miyaji, Y. 1992 Biodegradation of 2-Methylisoborneol by oligotrophic bacterium isolated from a eutrophied Lake. Water Sci. Technol. 25(2), 269-276.

Izaguirre, G., Taylor, W. D. \& Pasek, J. 1999 Off-flavor problems in two reservoirs, associated with planktonic Pseudanabaena species. Water Sci. Technol. 40(6), 85-90.

Jensen, S. E., Anders, C. L., Goatcher, L. J., Perley, T., Kenefick, S. \& Hrudey, S. E. 1994 Actinomycetes as a factor in odour problems affecting drinking water from the North Saskatchewan River. Water Res. 28(6), 1393-1401.

Khiari, D., Brenner, L., Burlingame, G. A. \& Suffet, I. H. 1992 Sensory gas-chromatography for evaluation of taste and odor events in drinking-water. Water Sci. Technol. 25(2), $97-104$.

Khiari, D., Suffet, I. H. \& Barrett, S. E. 1995 The determination of compounds causing fishy/swampy odors in drinking water supplies. Water Sci. Technol. 31(11), 105-112.

Khiari, D., Barrett, S. E. \& Suffet, I. H. 1997 Sensory GC analysis of decaying vegetation and septic odors. J. Am. Water Works Assoc. 89(4), 150-161.

Lin, T. -F., Wong, J. Y. \& Kao, H. P. 2002 Correlation of musty odor and 2-MIB in two drinking water treatment plants in South Taiwan. Sci. Total Environ. 289(1-3), 225-235.

Lloyd, S. W., Lea, J. M., Zimba, P. V. \& Grimm, C. C. 1998 Rapid analysis of geosmin and 2-methylisoborneol in water using solid phase micro-extraction procedures. Water Res. 32(7), $2140-2146$.

Mallevialle, J. \& Suffet, I. H. 1987 Identification and Treatment of Tastes and Odors in Drinking Water. AWWA Research Foundation and AWWA, Denver, Colorado.

McCarty, S., Chasteen, T., Marshall, M., Fall, R. \& Bachofen, R. I993 Phototrophic bacteria produce volatile, methylated sulfur and selenium compounds. FEMS Microbiol. Lett. 112, 93-98.

Rashash, D. M. C., Dietrich, A. M., Hoehn, R. C. \& Parker, B. C. I995 Influence of growth conditions on odor compound production by two chrysophytes and two cyanobacteria. Water Sci. Technol. 31(11), 165-172.

Rashash, D. M. C., Dietrich, A. M. \& Hoehn, R. C. 1997 FPA of selected odorous compounds. J. Am. Water Works Assoc. 89(4), 131-141.

Rosen, B. H., MacLeod, B. W. \& Simpson, M. R. 1992 Accumulation and release of geosmin during the growth phases of Anabaena circinalis (Kutz.) Rabenhorst. Water Sci. Technol. 25(2), 185-190.

Standard Methods for the Examination of Water and Wastewater I995 19th edition, American Public Health Association/ American Water Works Association/Water Environment Federation, Washington, DC.

Suffet, I. H., Khiari, D. \& Bruchet, A. 1999 The drinking water taste and odor wheel for the millennium: beyond geosmin and 2-methylisoborneol. Water Sci. Technol. 40(6), 1-13. 
Wajon, J. E. 1988 Bacterial causes of swampy odour and taste in drinking water. Water Qual. Bull. 13, 90-101.

Watson, S. B., Brownlee, B., Satchwill, T. \& Hargesheimer, E. E. 2000 Quantitative analysis of trace levels of geosmin and MIB in source and drinking water using headspace SPME. Water Res. 34(10), 2818-2828.

Yagi, M., Kajino, M., Matsuo, U., Ashitani, K., Kita, T. \& Nakamura, T. 1985 Odor problems in Lake Biwa. Water Sci. Technol. 15(6/7), 311-321.
Yang, M., Yu, J. W., Li, Z. L., Guo, Z. H., Burch, M. \& Lin, Tsair-Fuh 2008 Taihu Lake not to blame for wuxi's woes. Science 319(5860), 158.

Young, C. C. \& Suffet, I. H. 1999 Development of a standard method: analysis of compounds causing tastes and odors in drinking water. Water Sci. Technol. 40(6), 279-285.

Young, C. C., Suffet, I. H., Crozes, G. \& Bruchet, A. 1999 Identification of a woody-hay odor-causing compound in a drinking water supply. Water Sci. Technol. 40(6), 273-278.

First received 12 January 2009; accepted in revised form 25 August 2009 